\title{
PRIMER REGISTRO DE AMBLYOMMA AUREOLATUM (PALLAS, 1772) Y AMBLYOMMA OVALE KOCH, 1844 (ACARI: IXODIDAE) EN LA PROVINCIA DE SANTA FE, ARGENTINA
}

\author{
TARRAGonA, E. L. ${ }^{1,2}$; Eberhardt, M. A. T. ${ }^{1,4}$; ZURVERA, D. ${ }^{1,2}$; \\ Beldomenico, P. M. ${ }^{1,2,4}$ \& MASTROPAOLO, M. ${ }^{3}$
}

\begin{abstract}
RESUMEN
El 23 de noviembre del 2011 se colectaron ocho garrapatas sobre un ejemplar de Procyon cancrivorus hallado en la ruta provincial número 1, a $55 \mathrm{~km}$ al sur de la ciudad de Reconquista $\left(29^{\circ} 38^{\prime}\right.$ S, 59 $46^{\prime}$ W), Santa Fe. Los especímenes fueron identificados como una hembra de Amblyomma aureolatum (Pallas, 1772) y cuatro hembras y tres machos de Amblyomma ovale Koch, 1844. Este es el primer hallazgo de estas especies de garrapatas en la provincia de Santa Fe.

Palabras claves: Amblyomma aureolatum, Amblyomma ovale, Procyon cancrivorus, Santa Fe, Argentina.

\section{SUMMARY}

First record of Amblyomma Aureolatum (Pallas, 1772) and Amblyomma Ovale (Koch, 1844) (Acari: Ixodidae) in Santa Fe Province, Argentina.

Eight ticks were collected on November 23rd, 2011 from a Procyon cancrivorus found on the provincial road No. $1,55 \mathrm{~km}$ south from Reconquista city ( $29^{\circ} 38^{\prime}$ S, $\left.59^{\circ} 46^{\prime} \mathrm{W}\right)$, Santa Fe. The specimens were identified as a female Amblyomma aureolatum (Pallas, 1772) and four females and three males of Amblyomma ovale Koch, 1844. This is the first record of these species in Santa Fe province.

Key words: Amblyomma aureolatum, Amblyomma ovale, Procyon cancrivorus, Santa $\mathrm{Fe}, \mathrm{Ar}-$ gentina.
\end{abstract}

\footnotetext{
1.- Laboratorio de Ecología de Enfermedades. Facultad de Ciencias Veterinarias, Universidad Nacional del Litoral. Kreder 2805 (3080) Esperanza, Santa Fe. Email: evelina_tarragona@hotmail.com

2.- Grupo Capibara - FCV (UNL).

3.- Cátedra de Parasitología y Enfermedades Parasitarias. FCV (UNL).

4.- Consejo Nacional de Investigaciones Científicas y Técnicas (CONICET)

Manuscrito recibido el 23 de abril de 2012 y aceptado para su publicación el 14 de noviembre de 2012.
} 